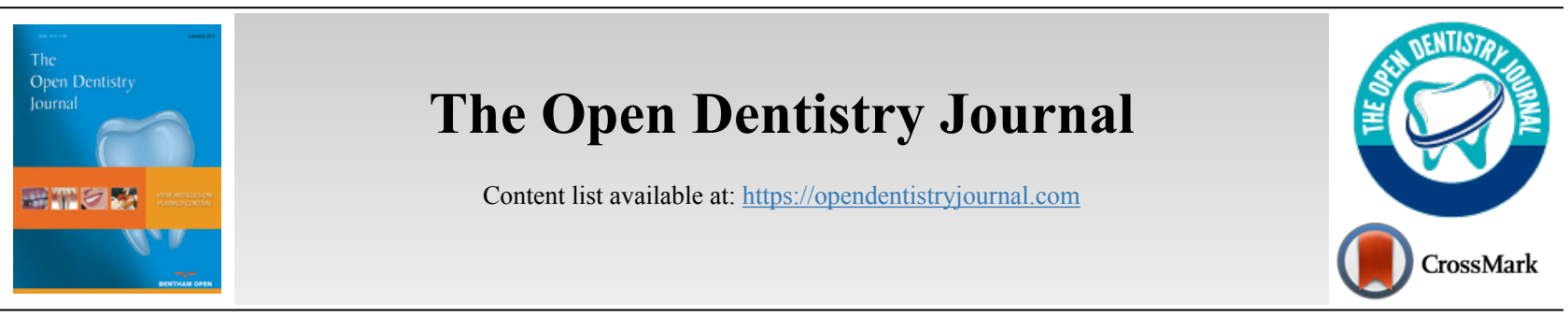

RESEARCH ARTICLE

\title{
Effectiveness of Randomized Controlled Field Trial Instructing Parents to Supervise Children on Tooth Brushing Skills and Oral Hygiene
}

\author{
Shukuru Zacharias ${ }^{1}$, Febronia Kokulengya Kahabukar, and Hawa Shariff Mbawalla ${ }^{2}$ \\ ${ }^{1}$ School of Medicine and Dentistry, University of Dodoma, Dodoma, Tanzania \\ ${ }^{2}$ Department of Orthodontics, Paedodontics and Community Dentistry, School of Dentistry, Muhimbili University of Health and Allied Sciences, \\ Dar es Salaam, Tanzania
}

\begin{abstract}
:
Background:

Educating parents on supervision of tooth brushing ensures effective plaque removal, healthy gums and attainment of tooth brushing skills.

Objective:

To evaluate the effect of educating parents about children's tooth brushing supervision on their own knowledge and act of supervision, their children's tooth brushing skills, plaque score and gingival health.

Methods:

Two arms cluster randomized controlled field trial among 8-9 years primary school pupils and their parents. The intervention trial was an educational leaflet on step by step supervision of children during tooth brushing. The outcomes were; improved tooth brushing skills, oral hygiene status and gingival health, parental awareness and supervision of children's tooth brushing. Data processing and statistical analysis was done using SPSS version 20.0. Frequency distribution for proportions, cross tabulations with Chi-square and adjusted binary logistic regression were performed.

Results:

A total of 237 pupils were followed to completion of the study. The odds of parents being aware and supervising children during tooth brushing were higher in the intervention group at follow-up $4.5(1.5,13.4)$ and $2.4(1.3,4.5)$ respectively. The unadjusted odds for good oral hygiene following intervention was $3.1(1.4,6.9)$ and that of tooth brushing skills $61.8(7.7,498.6)$. On adjusting with parental awareness and supervision of children during tooth brushing, odds of having tooth brushing skills increased to $88.2(9.2,847.4)$.

Conclusion:

Providing education to parents on children tooth brushing supervision effectively improved children's tooth brushing skills, plaque score and gingival health emanating from awareness and act of supervision improvements revealed on their part.
\end{abstract}

Key words: Supervised tooth brushing, Tooth brushing skills, Oral hygiene, Gingival health, Parental instructions, Parental awareness

\section{INTRODUCTION}

Supervised tooth brushing is the act of observing and directing children on how to perform tooth brushing. It refers

\footnotetext{
* Address correspondence to this author at the Department of Orthodontics, Paedodontics and Community Dentistry, School of Dentistry, Muhimbili University of Health and Allied Sciences, United Nations Road, $3^{\text {rd }}$ Floor Room 303, P.O. Box 65014, Dar es Salaam, Tanzania;

Tel: +255-222 150 564; Fax: +255-222 150465 ;

E-Mail: febby.kahabuka@gmail.com,fkahabuka@muhas.ac.tz
}

to instructing, directing and coaching children on how, whenand how many times to brush their teeth and overseeing the whole brushing activity. This ensures effective plaque removal, attainment of tooth brushing skills that may be retained through adulthood. Accordingly, it is recommended that for children aged seven to nine years; the parents should supervise them during tooth brushing $[1,2]$. In order for the parents to appropriately supervise their children's tooth brushing, they need to be aware of this role. Undesirably, some 
parents have been reported to be unaware of providing appropriate oral health care for their children [3] and others unaware of the existing national guidelines on tooth brushing [4]. As such Naidu et al. [5] recommended that; attempts for achieving parental ideal preventive care for their children should encompass effective dissemination of oral health information and practical health advice for families.

Parents' awareness on children's oral health has been shown to improve significantly after receiving instructions on specific aspects. Educational information, direct instruction, practice and peer-to-peer problem-solving brought about improvement in parents' knowledge on things to know about child's oral health from mean (S.D) $2.25(0.38)$ to $2.62(0.33)$ [6] and $4.80(1.12)$ to $6.68(0.47)$ [7]. Use of leaflets to educate mothers on first-aid actions following tooth avulsion resulted into $48 \%$ difference between the intervened and controls for replantation of avulsed tooth to $77.4 \%$ for general knowledge on tooth avulsion [8]. Likewise Danaei et al., [9], demonstrated significant post intervention improvement in parents' knowledge on normal occlusion and complication of oral habits in the intervened group following the use of pamphlets.

Information on parents who supervise or monitor their children during tooth brushing is scarce. Manohar et al., [10] reported $34 \%$ of the studied mothers of school going children to be monitoring their children's tooth brushing. A relatively smaller proportion $(26.5 \%)$ of Tanzanian primary school children reported that their parents supervised them during tooth brushing [11]. Children's tooth brushing was also reported to be prompted rather than being monitored by parents [12].

With respect to parental performances; regardless of the mode of delivery, education given to parents have resulted into desirable change in their practice related to their children's oral health $[5,7,13,14]$. Traditional oral health education and direct practical instructions resulted into increased proportion of parents who used baby tooth brushes to clean their children's teeth $(21.09 \%$ to $43.75 \%)$ and that of parents who brushed their children's teeth twice a day $(59 \%-89 \%)$ [6, 13]. Similarly Hoeft et al. [14], demonstrated a percentage increase of parents who performed all five aspects of tooth brushing in children according to professional guidelines from $13 \%$ to $44 \%$ after intervention. Utilizing motivational interview approach; Naidu et al. [5], reported a significant increase in mean child tooth brushing frequency.

On the other hand, a peer led community oral health education programme to parents displayed effectiveness in reducing debris and gingival inflammation among children in the intervened group. Those in the intervention group were $56 \%$ less likely to have debris $(\mathrm{OR}=0.44(0.22$ to 0.88$)$ and $66 \%$ to show signs of gingival inflammation $(\mathrm{OR}=0.34(0.19$ to 0.61 ) compared to controls [15].

Little has been done on supervised tooth brushing in Tanzania. Nevertheless, a recent study conducted whose approach was to directly intervene primary school children had small effect size and lacked support from the parents who may have been unaware of their role and not supervising the children [16]. It is an assumption that educating parents on the importance and step by step supervision of children's tooth brushing will result into a positive change in their awareness, practices as well as children's tooth brushing skills and oral hygiene. Therefore, this study was conducted to evaluate the effect of educating parents about children's tooth brushing supervision on their own knowledge and act of supervision, their children's tooth brushing skills, plaque score and gingival health.

\section{MATERIALS AND METHODS}

The study was a parallel cluster randomized controlled field trial with two arms; control and intervention with 6:6 cluster allocation ratio. In the intervention arm parents were given leaflets containing information on the importance of oral health and hygiene in a child, frequency and timings of toothbrushing, benefits of supervising children during tooth brushing and use of fluoridated toothpaste. It also contained pictorial instructions on step by step supervision of children during tooth brushing (Fig. 1). The parents were ascertained to have the leaflets, given clarification on how to use the leaflet whenever necessary and reminded to supervise their children via phone call every fortnight throughout the study period. The controls maintained their standard of dental care during the whole period of intervention.

The study was carried out in Kinondoni municipality Dar es Salaam city, Tanzania. The participants of the study were standard III primary school pupils aged 8-9 years and their parents. Children of this age seemed suitable for this kind of intervention because they are expected to brush their teeth on their own but doing so under parental supervision and have the ability to learn new skills and accepting new roles. Therefore, being able to understand, follow instructions and retain the gained knowledge and skills to adulthood.

The primary outcome of the study was improvement in tooth brushing skills and the secondary outcomes were; in children improvement in oral hygiene status and gingival health while in parents improvement in awareness and supervision of children's toothbrushing. These were collected through questionnaire (socio-demographics, awareness and practices), observation (tooth brushing skills) and clinical examination (plaque and gingival bleeding).

Tooth brushing skills was assessed through observing the children as they brushed their teeth in terms of brushed surfaces, sequence followed and type of strokes used. Having two out of three correct skill items was scored as 1 (skilled), not having or having one skill was scored 0 (not skilled). Improvement in oral hygiene status and gingival health were assessed by reduction in plaque and gingival bleeding scores. Plaque and gingival bleeding were scored on six index teeth namely $16,11,26,36,31$ and 46 as recommended by Green and Vermilion and Silness and Loe, respectively [17, 18]. Children who scored 0-3 out of 18 maximum scores for plaque or gingival bleeding were termed as having no plaque or healthy gingiva, respectively. While those scoring 4 and above were considered to have plaque or unhealthy gingiva. Improvement in parents' awareness and supervision of children's 


\section{TOOTH BRUSHING MESSAGE}

\section{Introduction:}

Children's oral health is an integral part of general health and has direct impact on children's growth and development. It is therefore important to maintain a good oral health.

Oral cleanliness may be achieved through proper oral hygiene practices, the most practiced being tooth brushing.

\section{Tooth Brushing:}

Your child is supposed to be supervised while brushing the teeth so that he/she does it properly. Teeth should be brushed twice a day, in the morning and at night before retiringto bed. It is adviced that the child uses a fluoridate toothpaste.

The chlld has to brush the upper jaw first then the lower Jaw.

On the upper jaw he/she has to start with the right side then anterior part followed by the left side while for the lower jaw the child has to start brushing the left side, then anterior part and finally the right side.

$\mathrm{He} /$ she has to brush the inner, outer and chewing surfaces by making short back and force movements to cover 2 to 3 teeth.

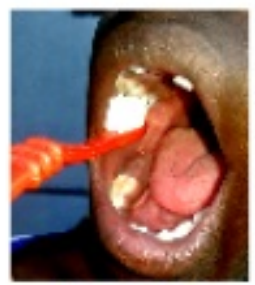

Brush the upper jaw first

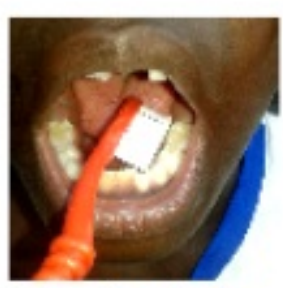

Then brush the lower jaw

\section{Surfaces}

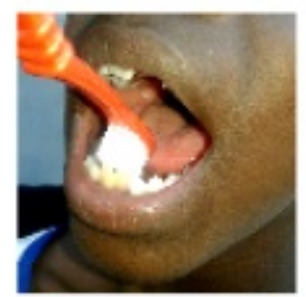

Brush the inner part

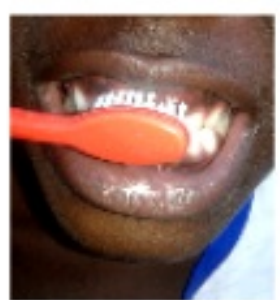

Brush the outer part

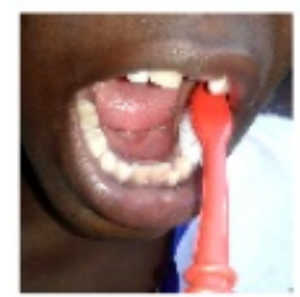

Brush the chewing surfaces 


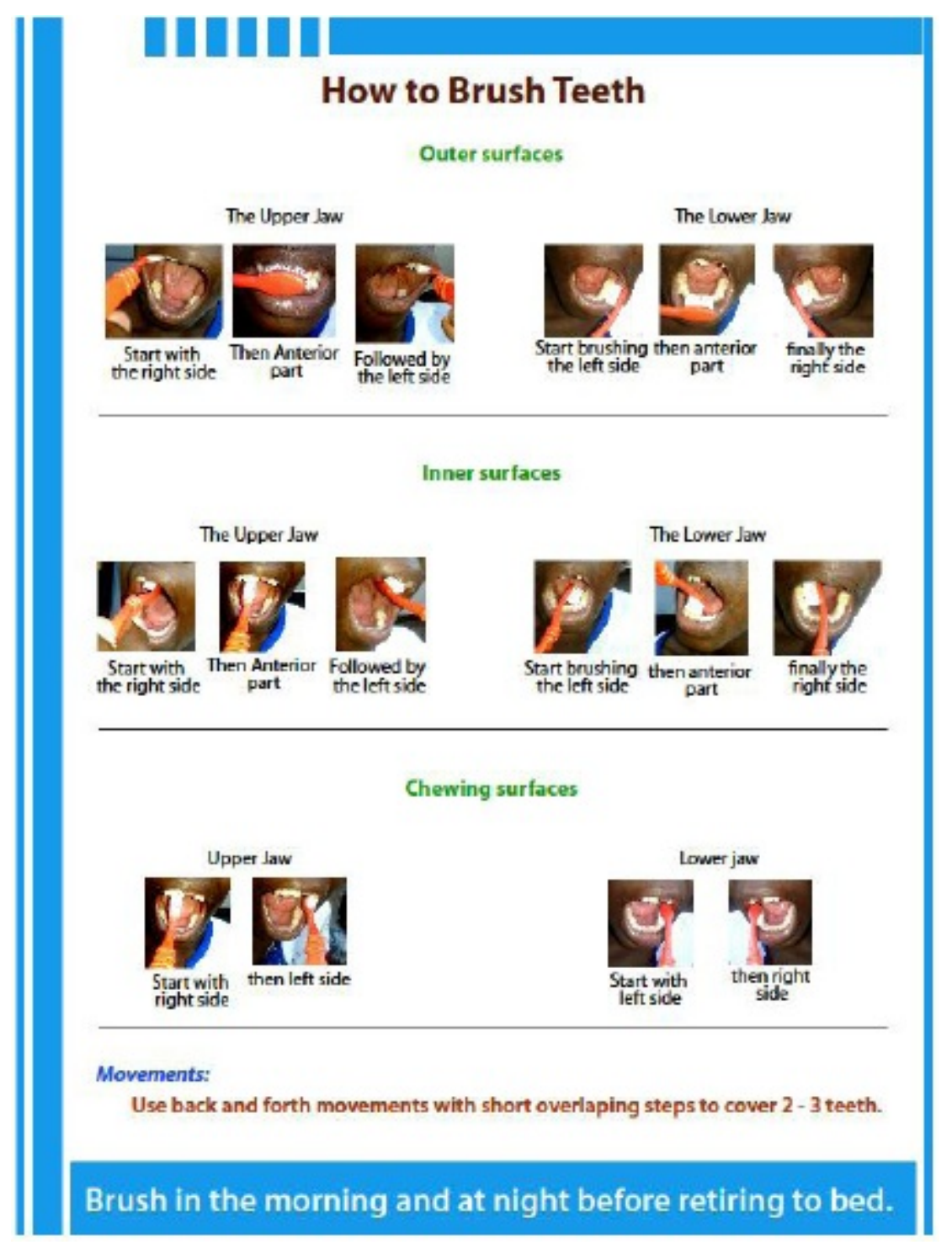

Fig. (1). A leaflet to parents on step by step instructions for tooth brushing.

tooth brushing was assessed by increase in correct responses on awareness and practice items. Parents who attained two to three correct knowledge statements scored 1 (being aware) while those who attained less than two correct knowledge statements scored 0 (not aware). Parents who supervised their children during tooth brushing in at least four out of six supervision items were scored 1 (child being supervised) while those supervising less than four items were scored 0 (child not being supervised).

The study sample was estimated on assumption that at baseline the proportion of children with plaque was $50 \%$ which was expected to decrease following intervention by $40 \%$, power of the study being $85 \%$ and $95 \%$ confidence. Employing a cluster sampling design school being a sampling unit with intra-cluster correlation coefficient (ICC) of 0.002, a total of 288 child-parent pairs in 12 clusters were expected to take part in the study. At school level (within the cluster) 20-30 individual pupils were selected using a systematic random sampling technique.
Simple randomization of clusters was done after baseline data collection whereby six schools were allocated to the control arm and the other six to the intervention group. Pupils in each of the schools automatically fitted to the interventions assigned to their school. Random allocation sequence of clusters was generated by an independent individual. The study was single blinded; that is only the participants were not aware of their intervention status because it was not feasible to blind the investigator who enrolled the participants and was the assessor.

MUHAS Institutional Review Board (IRB) granted ethical clearance whereas Kinondoni Municipal Council authority provided permission to undertake this study. Parents' informed consent and children's assertion were a pre-requisite for enrolment in this study.

Data processing and statistical analysis was done using a computer software program SPSS version 20.0. Frequency distributions for proportions and cross tabulations with $C h i$-square 
were done to assess statistical differences in sociodemographics and intervention outcome variables of the two intervention arms. To examine for the differences between the groups at two-time points (baseline and follow up) adjusted binary logistic regression was performed reported in odds ratio and $95 \%$ confidence interval. Adjustment was done to cater for the effect of socio-demographics and parental awareness and supervision during tooth brushing on observed changes. $P$ value of less than 0.05 was set as the level of statistical significance.

\section{RESULTS}

At the time of the study Kinondoni district had 78 public primary schools where through convenient sampling 12 schools were selected to take part in this study. Based on the research objectives, standard three pupils were targeted. At each school systematic sampling was used to select 24 pupils in order to attain the intended sample size (288). All selected pupils were invited to participate and issued letters of informed consent for their parents to consent. Forty one pupils did not return signed consent form, therefore were dropped leaving a total of 247 pupils whose baseline data were collected.
Randomization was done immediately after baseline data collection into two groups with equal number of six clusters each. In the control group they were 130 and the intervention had 117 pupils who received respective interventions. During the follow-up period 10 pupils ( 3 intervention and 7 control) were lost to follow-up ultimately 237 pupils completed the study (Fig. 2).

Recruitment of study participants was on $08^{\text {th }}$ to $13^{\text {th }}$ January, followed by baseline data collection from $17^{\text {th }}$ to $30^{\text {th }}$ January 2018 and followed up until $20^{\text {th }}$ April 2018. The study ended as planned after collection of follow-up data.

The participants' socio-demographic characteristics by the intervention arms are presented in Table. 1. The $p$-values for the differences between the intervention and control groups for all the socio-demographics ranged from 0.183 to 0.989 , thus the groups were not statistically significant different from each other. Likewise, at baseline primary and secondary outcomes except toothbrushing skills were not statistically significant different between the intervened groups compared to the controls. The difference noted on children's toothbrushing skills revealed higher proportion of skilled participants in the intervention group than the controls (Table. 2).

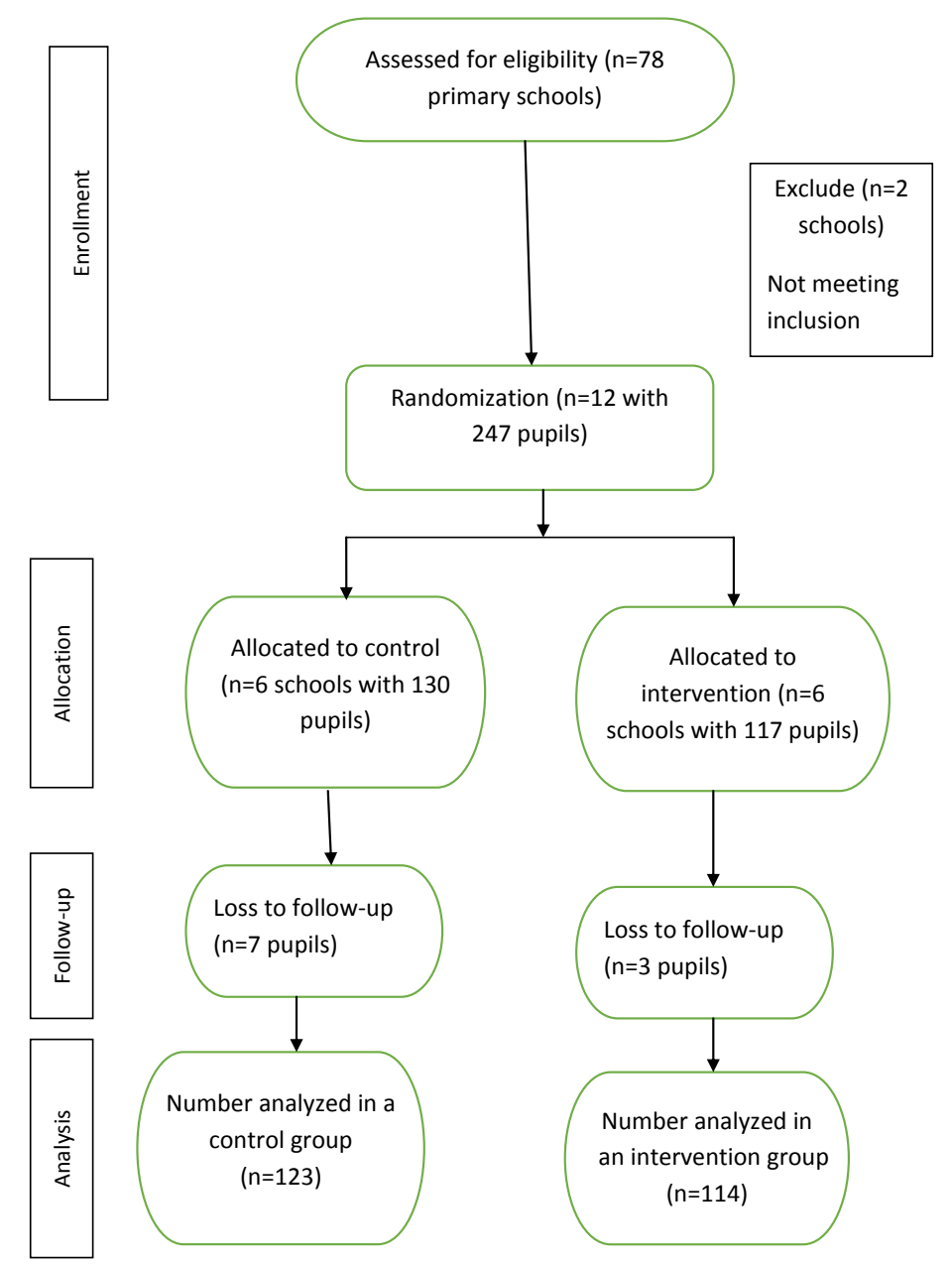

Fig. (2). A flow diagram of the trial progress. 
Table 1. Frequency distribution of socio-demographic characteristics by intervention arms at baseline (n=247).

\begin{tabular}{|c|c|c|c|c|}
\hline Variable & Categories & Intervention \%(n) & Control \%(n) & $P$-value \\
\hline \multirow{2}{*}{ Child's age } & 8 years & $39.3(46)$ & $31.5(41)$ & 0.201 \\
\hline & 9 years & $60.7(71)$ & $68.5(89)$ & - \\
\hline \multirow[t]{2}{*}{ Child's sex } & Female & $59.8(70)$ & $58.5(76)$ & 0.827 \\
\hline & Male & $40.2(47)$ & $41.5(54)$ & - \\
\hline \multirow{2}{*}{$\begin{array}{l}\text { Mother's highest education } \\
\text { attained }\end{array}$} & Primary or less than primary school & $66.7(78)$ & $63.1(82)$ & 0.555 \\
\hline & Secondary education or beyond & $33.3(39)$ & $36.9(48)$ & - \\
\hline \multirow[t]{2}{*}{ Father's highest education attained } & Primary or less than primary school & $51.3(60)$ & $57.7(75)$ & 0.312 \\
\hline & Secondary education or higher & $48.7(112)$ & $42.3(55)$ & - \\
\hline \multirow[t]{2}{*}{ Mother's occupation } & $\begin{array}{c}\text { Have no income generating activities } \\
\text { outside home }\end{array}$ & $28.2(33)$ & $36.2(47)$ & 0.183 \\
\hline & $\begin{array}{c}\text { Have income generating activities outside } \\
\text { home }\end{array}$ & $71.8(84)$ & $63.8(83)$ & - \\
\hline \multirow[t]{2}{*}{ Father's occupation } & Self-employed or small-scale business & $43.6(51)$ & $44.6(58)$ & 0.871 \\
\hline & Employed or business men & $56.4(66)$ & $55.4(72)$ & - \\
\hline \multirow{2}{*}{$\begin{array}{l}\text { Children below } 10 \text { years in the } \\
\text { family }\end{array}$} & One child & $37.6(44)$ & $37.7(49)$ & 0.989 \\
\hline & Two or more children & $62.4(73)$ & $62.3(81)$ & - \\
\hline
\end{tabular}

Table 2. Frequency distribution of children's and parents' outcome variables by intervention arms at baseline (n=237).

\begin{tabular}{|c|c|c|c|c|}
\hline Variable & Categories & Intervention \%(n) & Control \%(n) & $P$-value \\
\hline \multirow{2}{*}{ Children's oral hygiene } & No Plaque & $41.2(47)$ & $38.2(47)$ & 0.366 \\
\hline & Plaque & $58.8(67)$ & $61.8(76)$ & - \\
\hline \multirow[t]{2}{*}{ Children's gingival health } & Healthy gingiva & $69.3(79)$ & $59.3(73)$ & 0.072 \\
\hline & Bleeding & $30.7(35)$ & $40.7(50)$ & - \\
\hline \multirow[t]{2}{*}{ Children's tooth brushing skills } & Skilled & $14.0(16)$ & $3.3(4)$ & 0.003 \\
\hline & Unskilled & $86.0(98)$ & 96.7 (119) & - \\
\hline \multirow{2}{*}{$\begin{array}{c}\text { Parents' awareness on children's } \\
\text { tooth } \\
\text { brushing supervision }\end{array}$} & Aware & $80.7(92)$ & $79.7(98)$ & 0.487 \\
\hline & Not aware & $19.3(22)$ & $20.3(25)$ & - \\
\hline \multirow{2}{*}{$\begin{array}{l}\text { Parents' supervision of children's } \\
\text { tooth brushing }\end{array}$} & Supervise & $54.4(62)$ & $52.8(65)$ & 0.457 \\
\hline & Do not supervise & $45.6(52)$ & $47.2(58)$ & - \\
\hline
\end{tabular}

The analysis was by the original assigned groups. All the outcome variables at follow-up were statistically significantly different between the intervention and controls. Specifically, higher proportions of children in intervention arm had no plaque, healthy gingiva and tooth brushing skills compared to the controls. Similarly, higher proportions of parents in the intervention arm were aware and supervised their children during tooth brushing than those in the control arm (Table. 3).

The odds of parents being aware of children supervision during toothbrushing was higher in the intervention group at follow-up $4.5(1.5,13.4)$ as compared to the baseline $0.7(0.3$, 1.5) regardless of their sociodemographic status. Likewise, there were higher odds (2.4) for parents to supervise their children during toothbrushing after intervention than it was at baseline (0.9) (Table. 4).

The odds of having tooth brushing skills and good oral hygiene were higher in intervention group at follow-up compared to baseline.With the exception of tooth brushing skills, the odds of other outcome variables did not change markedly when controlled for parental socio-demographics, their awareness and supervision of children during tooth brushing. The unadjusted odds of having tooth brushing skills $61.8(7.7,498.6)$ increased with socio-demographics $65.2(8.2$, $520.3)$ and substantially so with parental awareness and supervision of children during tooth brushing $88.2(9.2,847.4)$,

Table 3. Distribution of children's and parents' outcome variables by intervention arms at follow up (n=237).

\begin{tabular}{|c|c|c|c|c|}
\hline Variable & Categories & Intervention \%(n) & Control $n=\%(n)$ & $P$-value \\
\hline \multirow{2}{*}{ Children's oral hygiene } & No Plaque & $76.3(87)$ & $35.8(44)$ & 0.001 \\
\hline & Plaque & $23.7(27)$ & $64.2(79)$ & - \\
\hline \multirow[t]{2}{*}{ Children's gingival health } & Healthy gingiva & $87.7(100)$ & $51.2(63)$ & 0.001 \\
\hline & Bleeding & $12.3(14)$ & $48.8(60)$ & - \\
\hline
\end{tabular}


(Table 3) contd.....

\begin{tabular}{|c|c|c|c|c|}
\hline Variable & Categories & Intervention\%(n) & Control $n=\%(n)$ & $P$-value \\
\hline \multirow[t]{2}{*}{ Children's tooth brushing skills } & Skilled & $47.4(54)$ & $1.6(2)$ & 0.001 \\
\hline & Unskilled & $52.6(60)$ & $98.4(121)$ & - \\
\hline \multirow{2}{*}{$\begin{array}{l}\text { Parents' awareness on children's } \\
\text { tooth brushing supervision }\end{array}$} & Aware & $95.6(109)$ & $82.1(101)$ & 0.001 \\
\hline & Not aware & $4.4(5)$ & $17.9(22)$ & - \\
\hline \multirow{2}{*}{$\begin{array}{l}\text { Parents' supervision of children's } \\
\text { tooth brushing }\end{array}$} & Supervise & $79.8(91)$ & $59.3(73)$ & 0.001 \\
\hline & Do not supervise & $20.2(23)$ & $40.7(50)$ & - \\
\hline
\end{tabular}

Table 4. Unadjusted and adjusted Odds Ratio (OR) and 95\% CI for parental awareness and supervision of children during tooth brushing at baseline and follow up.

\begin{tabular}{|c|c|c|c|}
\hline Variable & Categories & $\begin{array}{c}\text { Unadjusted Odds Ratio } \\
\text { (OR) (95\% CI) }\end{array}$ & $\begin{array}{c}\text { Adjusted by Socio-Demographics } \\
\text { Odds Ratio (OR) (95\% CI) }\end{array}$ \\
\hline \multirow{2}{*}{ Parental awareness at baseline } & Control & 1 & 1 \\
\hline \multirow{2}{*}{ Parental awareness at follow-up } & Intervention & $0.7(0.3,1.5)$, & $0.7(0.3,1.4)$ \\
\cline { 2 - 4 } & Control & 1 & 1 \\
\hline Parental supervision at baseline & Intervention & $4.5(1.5,13.4)^{*}$ & 1 \\
\cline { 2 - 4 } & Control & $0.9(0.5,1.5)$ & $0.8(0.5,1.5)$ \\
\hline Parental supervision at follow-up & Intervention & 1 \\
\cline { 2 - 4 } & Control & $2.4(1.3,4.5)^{*}$ & $2.0)$ \\
\hline
\end{tabular}

Key: ${ }^{*} P=0.01$,

Table 5. Unadjusted and adjusted Odds Ratio (OR) for children's tooth brushing skills, oral hygiene and gingival health at baseline and follow up.

\begin{tabular}{|c|c|c|c|c|}
\hline Variable & Categories & $\begin{array}{c}\text { Unadjusted Odds } \\
\text { Ratio (OR) } \\
\mathbf{9 5 \% ( C )}\end{array}$ & $\begin{array}{c}\text { Adjusted by Parental Socio- } \\
\text { demographics Odds Ratio } \\
\text { (OR) (95\% CI) }\end{array}$ & $\begin{array}{c}\text { Adjusted by Parental Socio- } \\
\text { demographics, Awareness } \\
\text { and Practices Odds Ratio } \\
\text { (OR) (95\% CI) }\end{array}$ \\
\hline \multirow{2}{*}{ Tooth brushing skills at baseline } & Control & 1 & 1 & 1 \\
\cline { 2 - 5 } & Intervention & $0.3(0.03,3.3)$ & $0.3(0.03,4.3)$ & $0.4(0.02,5.3)$ \\
\hline \multirow{2}{*}{ Tooth brushing skills at follow up } & Control & 1 & 1 & 1 \\
\cline { 2 - 5 } & Intervention & $61.8(7.7,498.6)^{* *}$ & $65.2(8.2,520.3)^{* *}$ & $88.2(9.2,847.4)^{* *}$ \\
\hline \multirow{2}{*}{ Good oral hygiene at baseline } & Control & 1 & 1 & 1 \\
\cline { 2 - 5 } & Intervention & $0.5(0.2,1.2)$ & $0.6(0.3,1.3)$ & $0.5(0.2,1.2)$ \\
\hline \multirow{2}{*}{ Good oral hygiene at follow up } & Control & 1 & 1 & $3.6(1.5,8.3)^{*}$ \\
\cline { 2 - 5 } & Intervention & $3.1(1.4,6.9) *$ & $3.3(1.5,7.4)^{*}$ & 1 \\
\hline \multirow{2}{*}{ Healthy gingiva at baseline } & Control & 1 & 1 & $0.8(0.3,1.8)$ \\
\cline { 2 - 5 } & Intervention & $0.8(0.4,1.7)$ & $0.8(0.4,1.8)$ & 1 \\
\hline \multirow{2}{*}{ Healthygingivaat follow up } & Control & 1 & 1 & $2.0(0.8,4.8)$ \\
\cline { 2 - 5 }
\end{tabular}

Table 5. However, parental awareness on children's supervision during tooth brushing remained to be statistically significantly higher $7.7(1.8,34.0)$ rather than a confounder as was expected when the three children's outcome variables (tooth brushing skills, oral hygiene and gingival health) were involved in the model.

\section{DISCUSSION}

This study reports on the effectiveness of creating parental awareness and skills on supervising tooth brushing hence attaining children's appropriate tooth brushing skills and oral hygiene. The study used cluster design in sampling and randomization; this might have resulted into the presented wider
$95 \%$ confidence intervals which minimizes the precision of the point estimates. To cater for the effect of the clusters, Intracluster Correlation Coefficient (ICC) was employed in sample estimation and using smaller cluster sizes. Moreover, a slightly higher proportion of participants in the intervention group had tooth brushing skills than controls at baseline. This could have resulted into overestimation of the primary intervention outcome at follow-up. The bias was addressed using a stepwise adjusted logistic regression by controlling the obtained effect size using parental awareness and supervision during tooth brushing as confounders.

The findings of this study can be generalized to both rural and urban communities which are served by oral health 
personnel and their children are day scholars ensuring daily interaction with parents. In countries with no prevailing programs to educate parents on their responsibilities in children's oral health and no well established oral health promotive activities, the findings are suitable. They are also generalizable to parents of both low and high socio-economic classes provided they are able to read and follow simple instructions. The culture of parents being part of children's learning and schooling which ensures direct communication between parents, children and teachers (school) is mandatory for our protocol's applicability.

The lack of statistical significant differences between the intervention group and controls at baseline in both sociodemographic variables and study outcomes ensures that randomization was well achieved hence any subsequent differences after intervention are accounted to the effect of the intervention trial. This is among the strengths of the study, that it is internally valid.

The intervention produced expected changes among the intervened participants compared to controls which are revealed by higher proportions of intervened children having good oral hygiene, healthy gums and to have gained tooth brushing skills at follow-up. Our findings are similar to those of Gibbs $e t$ al. [15], who reported that parental peer led community oral health education brought about improved children's debris score and gingival health. Additionally, the change due to intervention is evidenced by more parents who received leaflets (intervened) being aware and supervising their children during tooth brushing compared to their counterparts. Comparable findings were reported by Manchanda et al. [13], and Huebner et al. [6].

The study intervention on children supervision during tooth brushing given in form of instructions to parents through leaflets complemented by phone call resulted into improvement in their awareness and practice of supervising children at follow-up. The improvements noted were not influenced by the parents' socio-demographics indicating that the positive changes observed were due to intervention instituted. Analogous findings were reported earlier by Huebner et al. [6], and Makvandi et al. [7], though Gibbs et al. [15], reported lack of statistical significant differences in parental oral health knowledge between parents who received peer educator led community education and controls. Educational materials have earlier on been shown to be effective in increasing parents' awareness in children's oral health issues. Specifically, parents' knowledge increased following use of leaflet on knowledge of tooth avulsion [8] and that of educational pamphlet about normal occlusion and complications of oral habits [9].

At follow-up, children whose parents received intervention package improved in tooth brushing skills and oral hygiene status. The noted improvement signifies the effectiveness of the intervention in creating children's skills and their ability to remove plaque. The improvement in oral hygiene remained virtually the same even when adjusted for parental sociodemographics, awareness and supervision of children during tooth brushing while that of tooth brushing skills increased remarkably. Increase in odds of tooth brushing skills displayed after adjusting for parental socio-demographics, awareness and supervision of children during tooth brushing implies the importance of parents' role in enhancing children's tooth brushing skills. Our inference is in line with the finding of Collet et al. [19], that parents' child behavior management skills are associated with better child oral health. Furthermore, parents' awareness proved to be a key in the improvement of children's tooth brushing skills and oral hygiene indicating the importance of empowering parents on children's oral hygiene practices.

\section{CONCLUSION}

Providing education to parents on children tooth brushing supervision effectively improved children's tooth brushing skills, plaque score and gingival health emanating from awareness and act of supervision improvements revealed on their part. The magnitude of improvement in tooth brushing skills was stronger than of the other outcomes.

\section{RECOMMENDATION}

Governments to adopt the approach in their endeavor of instilling children's proper tooth brushing practices and gingival health. Further innovative studies in this field are recommended.

\section{LIST OF ABBREVIATIONS}

$$
\begin{aligned}
& \text { ICC }=\text { Intra-cluster Correlation Coefficient } \\
& \text { IRB }=\text { Institutional Review Board } \\
& \text { MUHAS }=\text { Muhimbili University of Health and Allied Sciences } \\
& \text { SPSS }=\text { Statistical Package for Social Sciences } \\
& \text { ETHICS APPROVAL AND CONSENT TO PART- } \\
& \text { ICIPATE }
\end{aligned}
$$

MUHAS Institutional Review Board (IRB) granted ethical clearance whereas Kinondoni Municipal Council authority provided permission to undertake this study.

\section{HUMAN AND ANIMAL RIGHTS}

No animals were used in this research. All human research procedures followed were in accordance with the ethical standards of the committee responsible for human experimentation (institutional and national), and with the Helsinki Declaration of 1975, as revised in 2013.

\section{CONSENT FOR PUBLICATION}

Parents' informed consent and children's assertion were a pre-requisite for enrolment in this study.

\section{FUNDING}

The Tanzanian Government supports through the University of Dodoma for funding the study.

\section{CONFLICT OF INTEREST}

Authors declare no conflict of interest, financial or otherwise. 


\section{ACKNOWLEDGEMENTS}

Our gratitude to all study participants for their time and cooperation, MUHAS for technical support.

\section{REFERENCES}

[1] Koch G, Poulsen S, Espelid I, Haubek D, Eds. Pediatric dentistry: A clinical approach. John Wiley \& Sons 2017.

[2] Mbawala HS, Machibya FM, Kahabuka FK. Assorted errands in prevention of children's oral diseases and conditions.Emerging Trends in Oral Health Sciences and Dentistry. InTech Open 2015.

[http://dx.doi.org/10.5772/59768]

[3] Rothnie JJ, Walsh CA, Wang MJ, Morgaine KC, Drummond BK. An exploratory study of pregnant women's knowledge of child oral health care in New Zealand. N Z Dent J 2012; 108(4): 129-33. [PMID: 23477011]

[4] Marshman Z, Ahern SM, McEachan RRC, Rogers HJ, Gray-Burrows KA, Day PF. Parents' experiences of toothbrushing with children: A qualitative study. JDR Clin Trans Res 2016; 1(2): 122-30. [http://dx.doi.org/10.1177/2380084416647727] [PMID: 28879241]

[5] Naidu R, Nunn J, Irwin JD. The effect of motivational interviewing on oral healthcare knowledge, attitudes and behaviour of parents and caregivers of preschool children: An exploratory cluster randomised controlled study. BMC Oral Health 2015; 15(1): 101

[http://dx.doi.org/10.1186/s12903-015-0068-9] [PMID: 26328785]

[6] Huebner CE, Milgrom P. Evaluation of a parent-designed programme to support tooth brushing of infants and young children. Int J Dent Hyg 2015; 13(1): 65-73.

[http://dx.doi.org/10.1111/idh.12100] [PMID: 25070036]

[7] Makvandi Z, Karimi-Shahanjarini A, Faradmal J, Bashirian S. Evaluation of an oral health intervention among mothers of young children: A clustered randomized trial. J Res Health Sci 2015; 15(2): 88-93. [PMID: 26175290]

[8] Ghaderi F, Adl A, Ranjbar Z. Effect of a leaflet given to parents on knowledge of tooth avulsion. Eur J Paediatr Dent 2013; 14(1): 13-6. [PMID: 23597213]

[9] Danaei SM, Faghihi F, Golkari A, Saki M. The impact of an educational pamphlet on the awareness of parents about 4-6-year-old children's oral habits and dentofacial discrepancies. J Dent Res Dent
Clin Dent Prospect 2016; 10(1): 57.

[http://dx.doi.org/10.15171/joddd.2016.009]

[10] Manohar J, Mani G. Knowledge and attitude of parents regarding children's primary teeth \& their willingness for treatment. J Pharmaceutical Sci Res 2017; 9(2): 194.

[11] Mercy MA. Assessment of the effect of supervised tooth-brushing and use of plaque disclosing agent on oral health status of Primary School Pupils in Dar-es-salaam. 2017.

[12] Gill P, Stewart K, Chetcuti D, Chestnutt IG. Children's understanding of and motivations for toothbrushing: A qualitative study. Int J Dent Hyg 2011; 9(1): 79-86.

[http://dx.doi.org/10.1111/j.1601-5037.2010.00442.x] [PMID: 212268 55]

[13] Manchanda K, Sampath N, Sarkar AD. Evaluating the effectiveness of oral health education program among mothers with 6-18 months children in prevention of early childhood caries. Contemp Clin Dent 2014; 5(4): 478-83.

[http://dx.doi.org/10.4103/0976-237X.142815] [PMID: 25395763]

[14] Hoeft KS, Barker JC, Shiboski S, Pantoja-Guzman E, Hiatt RA Effectiveness evaluation of contra caries oral health education program for improving Spanish-speaking parents' preventive oral health knowledge and behaviors for their young children. Community Dent Oral Epidemiol 2016; 44(6): 564-76.

[http://dx.doi.org/10.1111/cdoe.12250] [PMID: 27517458]

[15] Gibbs L, Waters E, Christian B, et al. Teeth Tales: A communitybased child oral health promotion trial with migrant families in Australia. BMJ Open 2015; 5(6): e007321.

[http://dx.doi.org/10.1136/bmjopen-2014-007321] [PMID: 26068509]

[16] Maya MA. Effectiveness of supervised tooth-brushing and use of plaque disclosing agent on children's tooth-brushing skills and oral hygiene: A cluster randomized trial. EC Dental Sci 2018; 17: 1929-38.

[17] Greene JC, Vermillion JR. The simplified oral hygiene index. J Am Dent Assoc 1964; 68(1): 7-13.

[http://dx.doi.org/10.14219/jada.archive.1964.0034] [PMID: 140763 41]

[18] Löe H, Silness J. Periodontal disease in pregnancy I. Prevalence and severity. Acta Odontol Scand 1963; 21(6): 533-51.

[http://dx.doi.org/10.3109/00016356309011240] [PMID: 14121956]

[19] Collett BR, Huebner CE, Seminario AL, Wallace E, Gray KE, Speltz ML. Observed child and parent toothbrushing behaviors and child oral health. Int J Paediatr Dent 2016; 26(3): 184-92. [http://dx.doi.org/10.1111/ipd.12175] [PMID: 26148197]

\section{C) 2019 Zacharias et al.}

This is an open access article distributed under the terms of the Creative Commons Attribution 4.0 International Public License (CC-BY 4.0), a copy of which is available at: (https://creativecommons.org/licenses/by/4.0/legalcode). This license permits unrestricted use, distribution, and reproduction in any medium, provided the original author and source are credited. 